\title{
Research and Development of Preceding-Evaluation System of Rural Drinking Water Safety Project
}

\author{
Lian He and Jilin Cheng \\ Yangzhou University, Yangzhou, P. R. China \\ helian@yzu.edu.cn
}

\begin{abstract}
The preceding-evaluation plays a crucial role in guiding construction. Preceding-evaluation system of rural drinking water safety project includes four main contents: opportunity evaluation, necessity evaluation, feasibility evaluation and decision evaluation. Using multi-turns specialist consultation method, the paper mainly studies the decision evaluation. Modular system structure is designed according to system function analysis and target analysis. Based on system database as the basic information support, preceding-evaluation system is developed by object-oriented method. The syetem includes the functions of project information storage, project estimation, economic analysis and decision evaluation, it can provide reference for planning, design and construction management of rural drinking water safety project.
\end{abstract}

Keywords: rural drinking water safety; preceding-evaluation system; objectoriented method; decision optimization.

\section{Introduction}

Protection of rural drinking water safety directly relates to the health and safety of farmers. Implementation of rural drinking water safety project is an important foundation work of building a new socialist countryside and a harmonious society. According to the national capital construction program, construction of rural drinking water safety project needs to go through a feasibility study, preliminary design, construction design, construction and other sectors. Any of problems in the process of building may lead to failure and loss of construction projects, especially the early decisionmaking directly relates to success of the project. In order to ensure decision-making being objective, just and scientific, a rational preceding-evaluation system is needed.

Now preceding-evaluation works of rural drinking water safety project are not so standardized. There are irregular, incomplete evaluation index system, the lack of uniform evaluation criteria, complicated operation, with the qualititive evaluation as the main approach and evaluation only from the viewpoint of investment in current evaluation works, which lead to some planning and design of rural drinking water safety project extremely unreasonable, and even appear some reconstruction works. Although a lot of research work of evaluation system has been carried out in many domestic and international trades, but the existing evaluation results are often not directly applied $^{[1] \sim[4]}$. 
The preceding-evaluation system of rural drinking water safety project needs to be studied to further optimize engineering decisions and reduce blind or wrong investment. Appropriate preceding-evaluation system software needs to be developed to provide practical evaluation management tools, to facilitate the smooth progress of preceding-evaluation and to ensure the actual effect of project investment.

\section{Research of Preceding-Evaluation System of Rural Drinking Water Safety Project}

\subsection{Main Contents of Preceding-Evaluation of Rural Drinking Water Safety Project}

Preceding-evaluation is the general term for a variety of evaluation before project establishment. Its main task is to solve the contradiction between limited resources and unlimited demand through analyzing and confirming the necessity and feasibility of the project, and giving decision-makers the evaluation results of different options to choose. According to time, preceding-evaluation can be divided into opportunity evaluation, necessity evaluation, feasibility evaluation and decision evaluation ${ }^{[5]}$.

Opportunity evaluation is to predict and assess potential opportunities. Necessity evaluation is to evaluate necessity of the project. Rural drinking water safety project is designed to solve the problem of drinking water for rural residents and is a major livelihood project. It is very necessary to construct rural drinking water safety project, so opportunity evaluation and necessity evaluation are not specially carried out.

Feasibility evaluation is to evaluate project rationality from the aspects of technology, economy and operation condition, social and environmental influence. It includs four parts: technical feasibility, economic feasibility, operation condition, social and environmental influence evaluation.

\subsection{Decision Evaluation of Rural Drinking Water Safety Project}

Decision evaluation is to integrate special evaluation results and to optimize decision. There is no decision comprehensive evaluation index system of rural drinking water safety project at present, to better measure and compare project feasibility, and to provide quantitative standard and scale for scheme decision, decision evaluation index system is studied.

Index system is the scientific quantitative and qualitative expression of evaluation purpose, intent and will ${ }^{[6]}$. Firstly, the indexes should be chosen under the guidance of scientific concept of development and the idea of sustainable development; Secondly, the indexes which are easy to quantify, easy to access and easy to accurately determine should be chosen as far as possible; the content difficult to quantify can use qualitative index; Simultaneously, drinking water safety project involves a wide range and the large regional differences, so the indexes should be chosen on both universality and regional specificity.

Common methods of selecting indexes have expert scoring method, principal component analysis method, the method of according to the minimum mean square error 
to delete index, the method of according to the minimax deviation method to reduce the index, correlation coefficient method ${ }^{[7]}$. According to evaluation objective and rural drinking water safety project content and in accordance with the principles of evaluation index system, decision evaluation index system of rural drinking water safety project adopts the method of combining theoretical analysis and statistical analysis, indexes are selected by multi-turns specialist consultation method, that is, specific index system is determined through consultation with expert advice on evaluation, statistical processing, focused expert advice after several rounds of feedback from consultation. This method is anonymous, feedback and statistical. It fully utilizes the knowledge and experience of expert groups and its results are more in line with the objective situation.

Index system is a complex system, so decision evaluation index system of rural drinking water safety project is divided into target layer, criterion layer and index layer by layered frame structure. Target layer is the highest layer, embodies the comprehensive evaluation results and provides decision basis for the rural drinking water safety project. Criterion layer reflects evaluation results of different aspects of rural drinking water safety project, and includes four parts: technical feasibility, economic feasibility, operation condition, social and environmental influence evaluation. Index layer is the basis of the evaluation system and is constituted by the direct indexes of feasibility evaluation. Decision evaluation index system of rural drinking water safety project is showen in Table 1. Index weight is determined by experts consultation method.

Table 1. Decision evaluation index system of rural drinking water safety project

\begin{tabular}{|c|c|c|c|c|}
\hline \multirow{2}{*}{ Target layer } & \multicolumn{2}{|c|}{ Criterion layer } & \multicolumn{2}{|l|}{ Index layer } \\
\hline & Index name & Weight & Index name & Weight \\
\hline \multirow{18}{*}{$\begin{array}{c}\text { Decision } \\
\text { evaluation }\end{array}$} & \multirow{8}{*}{$\begin{array}{l}\text { Technical } \\
\text { feasibility }\end{array}$} & \multirow{8}{*}{0.40} & Planning convergence & 0.10 \\
\hline & & & Water source selection & 0.15 \\
\hline & & & Project scale & 0.15 \\
\hline & & & Overall scheme & 0.15 \\
\hline & & & Collection works & 0.10 \\
\hline & & & Purification works & 0.15 \\
\hline & & & $\begin{array}{c}\text { Transmission and distribution } \\
\text { works }\end{array}$ & 0.15 \\
\hline & & & $\begin{array}{l}\text { Application of new } \\
\text { technology }\end{array}$ & 0.05 \\
\hline & \multirow{4}{*}{$\begin{array}{l}\text { Economic } \\
\text { feasibility }\end{array}$} & \multirow{4}{*}{0.20} & Investment estimation & 0.40 \\
\hline & & & Financing & 0.30 \\
\hline & & & National economic evaluation & 0.20 \\
\hline & & & Financial evaluation & 0.10 \\
\hline & \multirow{3}{*}{$\begin{array}{l}\text { Operation } \\
\text { condition }\end{array}$} & \multirow{3}{*}{0.20} & Construction management & 0.30 \\
\hline & & & Operation management & 0.30 \\
\hline & & & Water quality detection & 0.40 \\
\hline & \multirow{3}{*}{$\begin{array}{l}\text { Social and } \\
\text { environmental } \\
\text { influence } \\
\text { evaluation }\end{array}$} & \multirow{3}{*}{0.20} & Social benefit & 0.40 \\
\hline & & & Economic benefit & 0.20 \\
\hline & & & Environmental sustainability & 0.40 \\
\hline
\end{tabular}




\section{Design of Preceding-Evaluation System of Rural Drinking Water Safety Project}

System design includes objective analysis and functional analysis, system development goals identified, system components determined and programme implementation.

\subsection{System Objectives and Functions}

The main objective of preceding-evaluation system of rural drinking water safety is to achieve opportunity evaluation, necessity evaluation, feasibility evaluation and decision evaluation functions, and to provide scientific decision management tools for rural drinking water safety project.

The specific objectives of evaluation system as follows: to achieve the basic project data input, query and output functions; to achieve evaluation data query and output functions; to achieve investment estimation and economic analysis functions; to achieve the special evaluation function and to achieve comprehensive evaluation function.

\subsection{System Components}

According to the objective analysis, system design adopts modular architecture. According to system functions, system is divided into engineering information module, project necessity evaluation module, project decision evaluation module, project investment benefit evaluation module, help module and other modules.

Click data entry button on the drop-down menu of the project information module, you can input basic information data. Click the information query button, you can query and modify all the basic information and evaluation information of the project evaluated.

Project necessity evaluation module can carry out opportunity evaluation and necessity evaluation.

Project decision evaluation module can input and modify the indexes and weights, and evaluate project decision. The indexes selection and input sub-menu can choose correspondence index system according to the different project types; The weight selection and input sub-menu can choose or revise the corresponding weight; The project comprehensive evaluation system establishes the fuzzy synthetic evaluation model and expert scoring method to carry out decision evaluation to achieve project technical and economic comparison and optimize project decision.

Project investment benefit evaluation module has investment estimation, economic evaluation and benefit analysis sub-menus. Click different menus, you can realize corresponding function.

Help module can provide users with instruction to help users operation and solve problems in time.

\subsection{System Implementation}

System is supported by database and supplemented by users-friendly interface and human-machine dialogue process. The whole system is divided into the database subsystem, the data input subsystem, data calculation subsystem, data output subsystem, error control subsystem and program help subsystem. The data input subsystem can achieve the basic project data input and evaluation information input, such as 
engineering information, engineering solutions and evaluation indexes. Data can be inputed by assignment control or selection control.

Data calculation subsystem can calculate project investment and input or output data through computational module interface.

Data output subsystem can output data in text or table format.

Error control subsystem throughout the entire system can touch off debugging code running with direct inputing some predefined event of control itself, or establish an interactive link debug object and data input system by message mechanism, timely report the error to users and protect system normal operation through customizng objects and encapsulating code within the object.

Program help subsystem penetrates every corner of the entire program process to provide user help information at any time.

\subsection{Data Organization}

All operations are launched around the database which is the core of the evaluation system. Comprehensive data is the premise of scientific management and good decision, the data of preceding-evaluation system database of rural drinking water safety project includes three categories: evaluation data, engineering information data and economic data.

Data design use object-oriented relational data structure, strictly followed relational schema normalization and meet the physical integrity, referential integrity, userdefined integrity principles.

Data encoding formats use record format and dynamic list format to ensure data sequential and random management. Data storage and management use two network nodes of combination of library and table.

\section{Development Approach of Preceding-Evaluation System of Rural Drinking Water Safety Project}

\subsection{Development Tools and Development Environment}

Visual FoxPro has strong object-oriented programming functions, users-friendly interface and easy operation features. Preceding-evaluation system of rural drinking water safety project uses the Visual FoxPro development platform, stores data using its powerful database management features, pulls object-oriented programming in evaluation system, and achieves cross-platform software integration with other software on the windows system.

Software help system uses HTML HEIP Workshop and FrontPage software. HTML HElP Workshop can be directly embedded applications and also run independently from the application. Document prepared has a similar interface with resource manager, which is easy to transfer files and browse web. FrontPage is easy to use and allows ordinary users to quickly write web. The project document in the software help system is prepared by FrontPage and compiled by the HTML HELP Workshop.

\subsection{Development Method}

System development methods have process-oriented traditional development method and object-oriented development method. 
Process-oriented development method focuses on the system functionality to be achieved, which establish system function structure and the corresponding program module structure with self-directed, the gradual functional decomposition approach. Once the program needs to be modified, this way has heavy workload and is easy to produce a new error to make program degradation.

Object-oriented development method is to make up the deficiency of traditional method. First it focuses on objects involving applied problems, establishes object structure and the sequence of events to solve the problem. Accordingly, it establishes class inheritance hierarchy to achieve the required functions through various news connection. Object-oriented development method can use specific software tools to directly complete the conversion from the object to the software architecture, solve the multiple complex converting mapping process from analysis and design to software module structure, shorten the development cycle, make the entire system stable and ensure the system will not be degraded due to changes.

Therefore, preceding-evaluation system of rural drinking water safety which uses object-oriented software development method is more conducive to the establishment and modification and have higher reliability and maintainability than traditional method.

\section{Application of Preceding-Evaluation System of Rural Drinking Water Safety Project}

Selecting rural drinking water safety project in Xuyi County in Jiangsu Province, the paper carris out decision evaluation with this evaluation system. Evaluation results is showen in Table 2.

This project design schemes have three types: new construction city-west surface water treatment plant; new construction city-east surface water treatment plant; joint

Table 2. Decision evaluation of rural drinking water safety project in Xuyi County in Jiangsu Province

\begin{tabular}{ccccc}
\hline Project scheme & $\begin{array}{c}\text { New } \\
\text { construction city- } \\
\text { west surface water } \\
\text { treatment plant }\end{array}$ & $\begin{array}{c}\text { New } \\
\text { construction city- } \\
\text { east surface water } \\
\text { treatment plant }\end{array}$ & $\begin{array}{c}\text { Joint water } \\
\text { supply of } \\
\text { ground water } \\
\text { treatment plants }\end{array}$ \\
\hline \multirow{2}{*}{ Special } & $\begin{array}{c}\text { Technical } \\
\text { feasibility } \\
\text { Economic }\end{array}$ & 36.8 & 30.8 & 32.8 \\
scores & $\begin{array}{c}\text { feasibility } \\
\text { Operation } \\
\text { condition } \\
\text { Social and } \\
\text { environmental } \\
\text { influence } \\
\text { evaluation }\end{array}$ & 20.0 & 14.0 & 18.4 \\
Decision evaluation \\
score
\end{tabular}


water supply of ground water treatmen plants. It's known by the evaluation results that the scheme of new construction city-west surface water treatment plant is the best and the scores of technical feasibility, economic feasibility, operation condition and comprehensive evaluation are all the highest.

The actual application shows that the index system is reasonable and that system operation is simple and convenient. It can greatly reduce the workload and improve objective accuracy of the evaluation results.

\section{Conclusion}

According to the objective analysis and functional analysis, system design adopts modular architecture. Function modules include engineering information module, project necessity evaluation module, project decision evaluation module, project investment benefit evaluation module, help module and other modules. They are independent and interrelated and keep system stable.

Preceding-evaluation system of rural drinking water safety uses simple manmachine dialog window and multi-page switching framework, sets help module to facilitate user operation.

System uses powerful VFP language to write programs and uses object-oriented development mothod to keep high maintenance and reliability.

The preceding-evaluation results are very important to project construction of rural drinking water safety, preceding-evaluation system of rural drinking water safety project can better measure and compare project feasibility, and provide reference for scientific decision.

\section{References}

1. Liu, J., Li, Y., Zhang, X.: Research on Synthetical Indexes System for Post Evaluation of Water-Saving Irrigation Project in Gansu Province and Effect Evaluation. Water Saving Irrigation (1), 31-34 (2010)

2. Xu, C.: Research on the Financial Evaluation of Transportation Companies. Orient Acadenve Forum (Special) 10, 126-130 (2001)

3. Zhou, L., Zhang, J., Liu, Q.: Study on the Performance Appraisal System for Chinese Water Supply Enterprises. Chian Water \& Wastewater 22(2), 75-78 (2006)

4. Yang, S., Gary, A.D.: Baycsian Estimation of Classified Mean Daily Traffic. Transportation Research Part A 36, 365-382 (2002)

5. Li, J.: Project Evaluation Methodology. Nankai University Press, Tianjin (2009) (in Chinese)

6. Zhang, X.: Theory and Method of Water Conservancy Investment Benefit Evaluation. China Water Power Press, Beijing (2005) (in Chinese)

7. Du, D., Pang, Q., Wu, Y.: Modern Comprehensive Evaluation Methods and Case Picking. Tsinghua University Press, Beijing (2008) (in Chinese) 